\title{
ENGAGING ELEMENTARY SCHOOL STUDENTS AND THEIR PARENTS IN AFTER-SCHOOL STEM ACTIVITIES
}

\author{
Yury A. Kuleshov, Ph.D. Student, Purdue Polytechnic Institute, ykuleshov@purdue.edu \\ Dr. Anne M. Lucietto, Associate Professor, Purdue Polytechnic Institute, lucietto@ purdue.edu
}

\begin{abstract}
The authors are implementing a program to engage elementary school students and parents in after-school STEM activities to promote technical disciplines and STEM career paths. Children from Hispanic communities are often left behind when promoting STEM among the youth. The program will be available in two languages, English and Spanish, to address the gap. The authors will conduct post-program surveys with the parents of the participating children to access participants' perception of STEM. The results will guide future STEM activities among elementary school students in the local community and be useful for other STEM teachers, who target Hispanic and other underrepresented minority (URM) populations in their everyday work.
\end{abstract}

\section{Program Overview}

The authors are implementing a program to engage elementary school students and parents in extra curricular activities to promote STEM. The program will start in January 2022, run on a monthly basis, and last until the end of the current school year. The program will continue in the 2022-2023 school year and beyond. A local YMCA partner will provide learning space, and recruit the participants.

At least four reasons exist to include both children and parents. First, if a family, especially a Hispanic one, does not realize STEM career opportunities, the children are likely to choose alternative career paths. Second, providing parents of non-STEM backgrounds with appropriate resources can help them get involved in their children's academic lives. Third, some children are potential first-generation STEM college students. Fourth, parent education, including available funding awareness, is a cornerstone of overall success in STEM recruitment among minorities.

An inclusive environment for the participants will be exercised through: 1) bilingual (English and Spanish) structure to maximize involvement of Hispanic families; 2) free attendance to eliminate possible financial constraints; and 3) the presence of a program team member with Hispanic roots to stimulate the participants' "relatability" (Aish et al., 2018), or feeling of belonging in STEM. While the program does not target Hispanic children alone, it aims to fill the gap in recruiting Hispanic children in STEM.

The participants will take part in five activities that demonstrate the laws of nature, their technological applications, and the associated STEM career paths. The activities will contain content from chemistry, physics (mechanics), and engineering (hydraulics; solar, and electric power).

\section{Anticipated Outcomes, and Future Research}

The authors anticipate the following program outcomes: 1) increased awareness of the local families, especially Hispanic families, of the STEM career paths for their children; 2) more children finding joy in STEM activities; and 3) more children choosing STEM careers in college. The authors will use the STEM Career Interest Survey (STEM-CIS) (Kier, Blanchard, Osborne, \& Albert, 2014) with parents to complete on behalf of their children post-program. The results will help to develop improvements for future program iterations.

\section{References}

Aish, N., Asare, P., \& Miskioğlu, E.E. (2018). People like me: Providing relatable and realistic role models for underrepresented minorities in STEM to increase their motivation and likelihood of success. 2018 IEEE Integrated STEM Education Conference (ISEC), 83-89. doi: 10.1109/ISECon.2018.8340510.

Kier, M. W., Blanchard, M. R., Osborne, J. W., \& Albert, J. L. (2013). The development of the STEM career interest survey (STEM-CIS). Research in Science Education (Australasian Science Education Research Association), 44(3), 461481. https://doi.org/10.1007/s11165-013-9389-3 